\title{
TRILHAS DE UM (IM)PROVÁVEL CAMINHO: DAS INCERTEZAS DA DOCÊNCIA ÀS (TRANS)FORMAÇÕES DO PIBID NO AMBIENTE ESCOLAR
}

Maria Andréa Angelotti Carmo ${ }^{1}$

Anderson Aparecido Gonçalves de Oliveira ${ }^{2}$

\begin{abstract}
RESUMO
Este trabalho tem por finalidade apresentar e refletir sobre ações desenvolvidas no âmbito do Programa Institucional de Bolsa de Iniciação a Docência (PIBID), uma ação política de formação de professores vinculado ao Ministério da Educação e Cultura (MEC) e gerido pela Coordenação de Aperfeiçoamento de Pessoal de Nível Superior (CAPES). Aqui destacamos o PIBID e seu impacto nos ambientes escolares. Para exemplificar, elegemos o vídeo documentário "Educação: transformando realidades", produto de um dos projetos desenvolvidos pelo PIBID Sub projeto História, vinculado a Universidade Federal de Uberlândia (UFU). Esta parceria propiciada entre universidade e educação básica é compreendida como importante parte do processo de formação de professores dinâmicos e com responsabilidade social.
\end{abstract}

Palavras-chave: PIBID. EJA.

\begin{abstract}
This work aims to present actions developed within the Programa Institucional de Bolsa de Iniciação a Docência (PIBID), a political action of teacher training linked to the Ministério da Educação e Cultura (MEC) and managed by the Coordenação de Aperfeiçoamento de Pessoal de Nível Superior (CAPES). Here we highlight the PIBID and its impact on school environments. To exemplify, we chose the documentary video "Education: transforming realities", product of one of the projects developed by PIBID Sub project History, linked to the Universidade Federal de Uberlândia (UFU). This partnership between university and basic education is understood as an important part of the process of training dynamic teachers with social responsibility.
\end{abstract}

Keywords: PIBID. EJA.

\footnotetext{
1 Docente no Instituto de História da Universidade Federal de Uberlândia. Coordenadora do Programa Institucional de Bolsa de Iniciação à Docência - PIBID - Subprojeto História 2014-2017. Brasil. E-mail: mc.angelotti@gmail.com

2 Doutorando em História pelo Programa de Pós-graduação em História da Universidade Federal de Uberlândia. Supervisor do Programa Institucional de Bolsa de Iniciação à Docência - PIBID subprojeto História 2014-2018, Brasil. E-mail: anderson_araguari@hotmail.com
} 
Maria Andréa A. Carmo, Anderson A. G. de Oliveira | p. X-Y Trilhas de um (im)provável caminho: das...

"Ensinar não é apenas transferir conhecimento, mas criar possibilidades para a sua produção ou a sua construção" (FREIRE, 1996, p. 25).

\section{BREVES CONSIDERAÇÕES:}

Os caminhos trilhados por cada um de nós nem sempre é aquele idealizado e sonhado durante a infância ou no momento em que acreditamos fazer a melhor escolha da nossa profissão. É uma trilha marcada por desafios, percalços, questionamentos e frustrações cotidianamente experienciados, mas também, dimensionada por horizontes de expectativas demarcada por um ensejo de transformação social. Esta é uma das perspectivas que se vislumbra a partir das experiências de coordenação ${ }^{3}$ e supervisão ${ }^{4}$ de licenciandos do Curso de História da Universidade Federal de Uberlândia que chegaram ao Programa Institucional de Iniciação à docência.

Ser professor nos dias atuais não se configura, pelo menos para a grande maioria, como uma profissão de prestígio. Inúmeras adversidades e dificuldades são encontradas pelos caminhos deste profissional a cada dia, a cada aula, a cada turma, a cada escola em que atua, a cada salário recebido ao final do mês. Ser professor nos dias atuais é estar em luta constante, às vezes uma luta solitária, haja vista que os encaminhamentos de uma educação moderna nos separa em áreas de conhecimento, como se não fizéssemos parte de um todo e como se cada conhecimento independesse do outro, quase uma lógica "matrix" em que dois mundos paralelos coexistem, tendo de um lado uma sociedade perfeita e sincronizada, uma grande engrenagem, na qual cada peça, se move conforme

\footnotetext{
${ }^{3}$ As reflexões aqui apresentadas se embasam também em resultados parciais de projetos e pesquisas sobre o Ensino de História que tiveram apoio da FAPEMIG e à qual agradecemos.

${ }_{4}^{4}$ Contamos, ainda, com o apoio do Laboratório de Pesquisa em Cultura Popular e Vídeo Documentário - DOCPOP ao qual o professor Anderson está vinculado como pesquisador.
} 
Maria Andréa A. Carmo, Anderson A. G. de Oliveira | p. X-Y Trilhas de um (im)provável caminho: das... determinado pelo sistema5; já o outro "lado da moeda" se constitui num submundo de constante luta para tentar "trazer à luz" a realidade e as falhas do sistema enxergando uma transformação da sociedade através da Educação e não uma prisão social institucionalizada como pretende aquele pelo mundo perfeito e atraente demonstrados em lindas propagandas de TV e financiadas pelos governos.

Mas, obviamente, a profissão docente não se faz apenas de desencantos, enfrentamentos e dificuldades. Faz-se também do envolvimento, do desejo de transformar a realidade, da busca por maior qualificação, continuidade da formação para melhor atendimento e atuação na escola, da inserção e da responsabilidade social assumida com a profissão.

Embrear-se no desafio da docência, nos dias atuais, tem sido considerada atitude de coragem e determinação, além de uma grande responsabilidade social. Constantemente nos deparamos com algumas perguntas como o clássico questionamento: "professor, se o salário é tão baixo, porque se tornou professor?". Por mais simples que pareça esta questão, não conseguimos responde-la de imediato. Talvez, a melhor resposta não seja em palavras, mas em atitudes.

Ser professor não se pauta em "transmitir conhecimento" ou "ensinar", simplesmente. Seria muita limitação de nossa parte acreditar que seja isso, afinal, antes de tudo nosso aluno é um sujeito, munido de experiências múltiplas que podem e devem ser consideradas no processo ensino-aprendizagem. Nós, professores, podemos ser entendidos e atuar como mediadores do processo formador e/ou intermediadores da aprendizagem.

O Programa Institucional de Bolsa de Iniciação a Docência (PIBID) tornouse parte fundamental nesse processo de formação. Com o objetivo, entre outros de:

\footnotetext{
${ }^{5}$ Uma referência ao filme Matrix. Direção de Lana Wachowski e Lilly Wachowski, Austrália e Estados Unidos, 1999.
} 
- elevar a qualidade da formação inicial de professores nos cursos de licenciatura, promovendo a integração entre educação superior e educação básica;

- inserir os licenciandos no cotidiano de escolas da rede pública de educação, proporcionando-lhes oportunidades de criação e participação em experiências metodológicas, tecnológicas e práticas docentes de caráter inovador e interdisciplinar que busquem a superação de problemas identificados no processo de ensino aprendizagem; ${ }^{6}$

Podemos dizer que os objetivos do Programa são audaciosos, para dizer o mínimo e, com a perspectiva de melhora na qualidade de ensino vemos que se constituiu em uma ferramenta imprescindível. Elevar a qualidade da formação inicial de professores, inserir os licenciandos no cotidiano das escolas públicas, contribuir para a articulação entre teoria e prática, elevar ainda, os índices de qualidade da educação básica constituem-se objetivos do Programa, mas principalmente, do Estado brasileiro. Este Programa veio em um momento importante, em um contexto educacional de grandes desafios e atuou como um sopro de possibilidades de inovação frente a um período em que a educação parece ter se tornado obsoleta, mergulhada em amarras e, ao mesmo tempo, em busca de técnicas e métodos que, de certo modo, tornaram o ambiente escolar pouco atrativo, um local "frio", "estático" e "distante" do sujeito aprendiz. A partir das ações realizadas com o PIBID refletimos sobre as possibilidades de se ter dinamizado o espaço escolar e seus sujeitos, buscando modificar o que nos parecia possível na prática cotidiana.

O Programa promove a articulação entre a Educação Superior e a Educação Básica, por meio das escolas e sistemas municipais e estaduais de ensino buscando estreitar os vínculos entre os futuros professores e a experiência da docência nas escolas da rede pública. Assim, o PIBID oportuniza uma aproximação nos ambientes escolares, como também tem contribuído para

\footnotetext{
6 PORTARIA № 096, DE 18 DE JULHO DE 2013 que Regulamenta o Programa Institucional de Bolsa de Iniciação à Docência.
} 
Maria Andréa A. Carmo, Anderson A. G. de Oliveira | p. X-Y Trilhas de um (im)provável caminho: das... repensar os procedimentos adotados na formação dos futuros licenciados. Essa via de mão dupla nos leva a um novo tempo na educação. O primeiro ponto claro é a aproximação e interação entre a universidade e a escola básica.

Historicamente, ao longo de décadas, a universidade se manteve distante da educação básica, concentrada na produção acadêmica, mas afastada das práticas escolares. Foi responsável pela elaboração de políticas, reformas educacionais, cursos de formação docente, formação continuada, entre outras ações que se voltavam para a pesquisa sobre a escola e não com a escola. Enfrentamos uma hierarquia entre quem produzia o conhecimento e quem o reproduzia, numa concepção de que cabia à escola o lugar da reprodução do conhecimento científico através das disciplinas e currículos e não como espaço da construção de conhecimento.

Em um primeiro momento, a possibilidade de estabelecimento e ampliação do diálogo entre a universidade e a escola básica, sendo o PIBID uma "ponte" nesse processo, impulsionou a viabilidade de um entendimento em que a teoria e a prática poderiam estar lado a lado, levando a dinamização do processo educacional e do espaço formador.

Esta compreensão dá-se pois, "percebendo a relação da escola e universidade como espaço de interação entre a ação e os discursos, simultaneamente, é possível pensar num processo de aprendizagem entre os dois campos de forma interdependente"(TAUCHEN; DEVEVHI; TREVISAN, 2014, p. 385). Interação e dinamicidade, são palavras que, para nós, expressam muito das ações e realizações possibilitadas pelo PIBID.

Em um segundo momento e, atrelado à aproximação entre a universidade e a escola pública de educação básica, o PIBID propiciou uma dinamização nos ambientes escolares em que atuamos, demonstrando as várias possibilidades educacionais que vão além da sala de aula, do conteúdo programático, da lousa e do giz. Um dos elementos principais foi observar o rompimento de barreiras que pareciam separar áreas de conhecimentos, espaços de atuação, linguagens e 
Maria Andréa A. Carmo, Anderson A. G. de Oliveira | p. X-Y Trilhas de um (im)provável caminho: das...

relações professor-aluno, licenciando do profissional, universidade da escola, enfim, participar efetivamente da dinamicidade do processo ensinoaprendizagem numa tentativa de acompanhar os passos rápidos e ágeis dos jovens de hoje.

Nesse processo, recordamos que a escola não é de quem passou por ela, não é patrimônio dos professores, tão pouco da direção escolar. A escola pertence àqueles que estão ali, naquele momento. Assim, não podemos conceber nossos alunos apenas como meros espectadores e sim como agentes de sua própria formação. O PIBID tornou possível, para nós professores e licenciandos, praticar o que Paulo Freire defendia:

Não devemos chamar o povo à escola para receber instruções, postulados, receitas, ameaças, repreensões e punições, mas para participar coletivamente da construção de um saber, que vai além do saber de pura experiência feito, que leve em conta as suas necessidades e o torne instrumento de luta, possibilitandolhe transformar-se em sujeito de sua própria história. (FREIRE, 1991, P. 16)

\section{O PIBID EM HISTÓRIA: UMA TRAJETÓRIA}

No ano de 2014 o Programa Institucional de Bolsa de Iniciação a Docência desembarcou na Escola Estadual Professor Ederlindo Lannes Bernardes, no Bairro Morumbi, uma área periférica do município de Uberlândia-MG. Naquele momento nossa equipe era composta pela coordenadora, um supervisor ${ }^{7}$ e sete licenciandos ${ }^{8}$ do curso de História da Universidade Federal de Uberlândia. O Bairro Morumbi está situado em uma região periférica, distante do centro da cidade e da Universidade, o que muitas vezes, é motivo para que esta instituição escolar do bairro seja preterida para realização de estágios supervisionados e outros projetos que seriam ali bem recebidos. Além disso, predominam entre os

\footnotetext{
7 Professor Mestre Anderson Aparecido Gonçalves de Oliveira

${ }^{8}$ Graduandos em História UFU: Fabiana, Éder, Lucas, Camila, Itamar, Jean, Rafael.
} 
Maria Andréa A. Carmo, Anderson A. G. de Oliveira | p. X-Y Trilhas de um (im)provável caminho: das...

moradores da cidade e do bairro alguns discursos preconceituosos pautados e divulgados em programas responsáveis por apresentar as notícias relacionadas a assassinatos, roubos, tráfico de drogas e os índices de violência na cidade. De certo modo, as representações que se tem do bairro e seus moradores acabam sendo percebidos dentro da sala de aula, na falta de perspectivas que alguns estudantes apresentam, ou mesmo, nas dificuldades de aprendizagem observadas.

A equipe do PIBID Subprojeto História, após análise prévia do levantamento de dados junto aos estudantes, teve a percepção de que seria necessário considerar as interpretações em relação à educação escolar, pois para muitos estarem ali já era uma grande conquista: o ato de se fazerem presentes no espaço escolar. O ponto de partida seria trabalhar o modo com que os alunos compreendiam a educação escolar, procurar observar suas expectativas e, quem sabe, apresentar-lhes possibilidades.

Na Escola Estadual Professor Ederlindo Lannes Bernardes, o PIBID foi desenvolvido com discentes da Educação de Jovens e Adultos do Ensino Médio $(\mathrm{EJA})^{9}$, uma realidade muito diferente daquela vivida pela maioria dos estudantes do ensino regular diurno. Homens, mulheres, solteiros, casados, separados, com filhos, trabalhadores empregados e desempregados, jovens e idosos. No processo de estabelecer um diálogo com estes estudantes, utilizamos como ferramenta principal o vídeo documentário "Caminhos da escola Paraná10", o qual retrata a dificuldade dos jovens e crianças do interior do estado do Paraná em acordar ainda de madrugada, caminhar cerca de 4 quilômetros para chegar à primeira condução que o levará até a escola, retornando já no início da tarde. Seja

\footnotetext{
${ }^{9}$ Para maiores discussões sobre a Educação de Jovens e Adultos na sociedade brasileira ver, entre outros: HADDAD; DI PIERRO, 2000 e 2010.

10 Documentário, 54 min. Produção: Maquina Produções (H.A. Passos Produções Cinematográficas). Diretor: Heloisa Passos. Resumo: "Caminho da escola" é um filme sobre escolhas que traduzem o desejo humano de ir além. Tendo como fio condutor o percurso de crianças para suas escolas, o filme propõe a revelação, sobretudo humana, da realidade de famílias que buscam na escola uma perspectiva de vida que, acreditam, a educação pode lhes oferecer. Para mais acessar: http://www.cultura.pr.gov.br/pagina-399.html
} 
Maria Andréa A. Carmo, Anderson A. G. de Oliveira | p. X-Y Trilhas de um (im)provável caminho: das...

pela distância percorrida até a escola, seja pelo trabalho no campo, muitos estudantes viram-se obrigados a abandonar os estudos.

Esta realidade se aproximava das experiências de muitos dos nossos estudantes que tiveram, em algum momento, que abandonar os estudos. A experiência se aproximava ainda, pelas dificuldades financeiras relatadas, a necessidade do trabalho para auxiliar nas contas de casa e o fato de estarem cursando a EJA. Não temos dúvida de que era grande a responsabilidade destes estudantes trabalharem o dia todo e, ao final, ainda conseguirem enfrentar uma outra jornada noturna, de estudos, em meio ao cansaço do labor diário.

A apresentação deste vídeo documentário provocou muitas reações e, vários alunos emocionados relataram que passaram por realidades próximas em suas cidades de origem ${ }^{11}$, o que nos comoveu durante a roda de conversa e, foi com esta atividade que percebemos a importância de conhecer nossos estudantes, saber sobre suas origens e considerar suas experiências no processo de ensinoaprendizagem. Uma roda de conversa sobre o vídeo-documentário deu início a uma nova etapa para àqueles sujeitos aprendizes, bem como para todos nós da equipe.

Ao longo de todo o ano letivo de 2014 realizamos várias ações com estes estudantes, projetos sobre política, discussões sobre o racismo, debates e atividades com o tema sustentabilidade entre outros que foram realizados também no ano de 2015 na Escola Estadual Lourdes de Carvalho ${ }^{12}$. Foram anos intensos e de grande interação e movimento nas escolas.

Movimento também para nós da equipe, que como num estalar de dedos nos vimos de volta, no início de 2016, ao local onde todo o trabalho com o PIBID

\footnotetext{
${ }^{11}$ O Bairro Morumbi em Uberlândia-MG configura-se em região periférica e grande parte dos seus moradores são oriundos de outras regiões do país, que procuram a cidade com a perspectiva de melhores empregos, condições de trabalho, melhores salários, enfim, uma vida melhor.

12 Estas atividades serão apresentadas, discutidas e analisadas em um outro momento. Vale ressaltar que o processo de designação de professores na rede pública de Minas Gerais leva a mudança de lotação de alguns supervisores do Programa e, assim, o PIBID Subprojeto História se fez presente na Escola Estadual Lourdes de Carvalho no ano de 2015.
} 
Maria Andréa A. Carmo, Anderson A. G. de Oliveira | p. X-Y Trilhas de um (im)provável caminho: das... iniciou, a Escola Estadual Professor Ederlindo Lannes Bernardes. A dinâmica e alocações docentes na rede pública estadual quando se é contratado, muitas vezes, é imprevisível. Mais uma vez, fomos bem recebidos na escola e no Bairro Morumbi mas, agora, com uma responsabilidade ainda maior, afinal a expectativa em relação aos trabalhos já desenvolvidos eram cada vez maiores. A equipe original de 2014, praticamente não existia no ano de 2016, pois no programa (PIBID) também temos uma movimentação/rotatividade de bolsistas, principalmente em razão da conclusão do curso $^{13}$. Levando em consideração a nova equipe e o fato de retornarmos a Educação de Jovens e Adultos, o primeiro passo foi apresentar os bolsistas (maioria iniciantes no curso de Graduação) ao EJA, estudando suas particularidades em relação ao ensino médio básico regular. A experiência de apresentar o vídeo-documentário foi retomada e realizada com as novas turmas, a roda de conversa emocionada ocorreu mais uma vez.

Diante disso, tivemos a iniciativa de convidar os próprios alunos da EJA para se apresentarem e contarem suas experiências por meio de um pequeno documentário. Preparamos a equipe de licenciandos para desempenhar o papel de entrevistador, cinegrafista, roteirista e, principalmente, que soubesse ouvir as narrativas de maneira atenciosa e respeitosa.

Um roteiro de perguntas fora organizado: por que tiveram que deixar os estudos; o que os levou a retornar para a escola após o período fora; o que almejavam para o futuro; quais dificuldades enfrentam para continuar estudando entre outras questões foram realizadas. Convidamos todos os estudantes a participarem e, durante o processo de pré-produção, solicitamos aos sujeitos aprendizes que colocassem no papel suas histórias de vida. Ali começamos a perceber que a cada traço do grafite no papel e a cada linha tínhamos mais do que relatos. Aqueles registros se constituíam em verdadeiros exemplos de determinação, superação e de que, às vezes a vida cobra um alto

\footnotetext{
${ }^{13}$ Neste ano de 2016 a equipe foi composta pelos seguintes alunos de graduação em História: Camila, Hugo, Crhistiane, Izabella, Geovan, Márcio e Kathelen.
} 
Maria Andréa A. Carmo, Anderson A. G. de Oliveira | p. X-Y Trilhas de um (im)provável caminho: das... preço pelas escolhas que fazemos pelo caminho. Caminho este retomado por esses sujeitos na Educação de Jovens e Adultos pelos mais variados motivos. Dentre os estudantes, escolhemos quatorze deles, levando em consideração a variação de idade e histórias de vida, sendo quatro homens e dez mulheres.

Escolhemos o espaço da biblioteca para registrar as experiências que seriam partilhadas conosco. Afinal, quantos livros ali não carregavam histórias e momentos marcantes a exemplo destes alunos que estavam prestes a abrir o diário de uma vida particular, enfrentando o medo, a vergonha e principalmente suas próprias histórias. Além da questão representativa em relação ao espaço, havia também a questão técnica em que a biblioteca nos viabilizava, em especial com relação a montagem dos equipamentos e a redução de ruídos externos, pois os materiais seriam gravados em dias comuns de aula. Os alunos que se dispuseram, vinham um a um e respondiam algumas de nossas questões em frente às câmeras e diante de nossa equipe. Este foi mais um momento de grande interação e emoção.

Nas narrativas de diferentes mulheres jovens, senhoras, dentre outras, eram constantes as lembranças de terem abandonado os estudos em decorrência de gravidez durante a adolescência, casamento ou a necessidade de trabalhar para incrementar a renda familiar. Entre os homens, a falta de oportunidade por morarem na zona rural na época em que poderiam estar estudando, a falta de interesse apareceu entre alguns, a jornada de trabalho assumida muito cedo, entre outros. Mas, todos, sem exceção, retornaram aos estudos por entenderem que estudar é fundamental, não somente para o mercado de trabalho, mas também como projeto de vida.

O que nos surpreendeu nestes depoimentos foi a coragem e determinação de cada um ali, que representava não somente suas próprias histórias de vida, mas tantos outros alunos e alunas que também fazem parte do Projeto Educação para Jovens e Adultos. O nome do documentário não poderia ser outro a não ser 
Maria Andréa A. Carmo, Anderson A. G. de Oliveira | p. X-Y Trilhas de um (im)provável caminho: das...

"Educação: transformando realidades"14, afinal é nisso que esta equipe sempre acreditou, pois o profissional da educação tem um enorme poder de transformação através do ensino e talvez, seja isso que fazemos, transformar realidades.

Pode parecer presunção da parte do professor fazer tal afirmação, mas quando olhamos o resultado de nossos trabalhos e esforços, encontrando alunos nos corredores de universidades, principalmente aqueles que terminaram seus estudos por meio da Educação de Jovens e Adultos, é, de algum modo gratificante. Percebemos naqueles momentos que podemos sim fazer a diferença na vida das pessoas se aproveitamos os interesses que eles trazem e lhes possibilitamos trilhar os caminhos do conhecimento científico.

Este foi um projeto especialmente emocionante. As lágrimas não estavam apenas nos olhos daqueles que falavam, mas principalmente naqueles que por de trás das câmeras se colocavam no lugar do outro. Em um dos depoimentos, um dos mais marcantes, uma aluna afirmava ter perdido uma vaga de emprego para lavar copos por não ter o ensino médio completo e, segundo ela, tratava-se de uma atividade corriqueira do lar de qualquer pessoa. Mas, para a aluna, foi justamente esse "não" recebido que a motivou a rever seus objetivos de vida e retomar seus estudos, pensando inclusive em um curso superior no futuro. Naquele momento todos da equipe tentavam disfarçar as lágrimas e rostos emocionados, afinal não éramos nós os protagonistas, mas a Jéssica e todos aqueles que aceitaram participar da atividade.

Após coletar os quatorze depoimentos, por meio de gravações de vídeo, veio a tarefa de edição em que se elegeu durante uma reunião entre a equipe, externar ao máximo a emoção daqueles depoimentos e do que sentimos durante o processo de gravação. Levar o espectador a ter uma pequena noção da multiplicidade e riqueza presente naquelas narrativas. Devemos destacar,

\footnotetext{
${ }^{14}$ Vídeo documentário "Educação: transformando realidades" disponível em: https://www.youtube.com/watch?v=0jZX2Ih-vNY\&t=2s
} 
Maria Andréa A. Carmo, Anderson A. G. de Oliveira | p. X-Y Trilhas de um (im)provável caminho: das... também, que em alguns destes momentos tivemos espaços para a descontração, assim decidiu-se atrelar tais momentos sem perder seu papel social e transformador.

As trilhas sonoras foram utilizadas de forma a dar destaque aos depoimentos, afinal, os atores do processo eram os sujeitos aprendizes, portanto as músicas não poderiam ter voz, apenas melodias que pudessem envolver o espectador. As melodias se revezavam em tons flutuantes, às vezes românticos ou em ritmos dançantes. Pois, nossas vidas são assim, envolventes e dinâmicas e naquela película tínhamos a responsabilidade de representar cada um dos alunos, mesmo aqueles que não tivessem participado do processo de gravação.

Realizado este trabalho, organizamos o lançamento do vídeodocumentário na escola. Foi um evento que contou com a participação e a presença do diretor Tiago Henrique Quintino, do Superintendente de Ensino Jakes Paulo Felix, da então Coordenadora geral do PIBID/UFU Regina Ilka Vieira Vasconcelos, inspetores escolares, analistas de educação, professores da escola, professores convidados, a equipe do PIBID subprojeto História responsável pelo trabalho e, acima de tudo, dos verdadeiros protagonistas, os estudantes participantes do projeto. E o local não poderia ser outro a não ser a Biblioteca, espaço no qual memórias e histórias se entrelaçaram em meio a lágrimas e sorrisos.

Após a exibição do vídeo documentário observamos olhos brilhantes ao rosto de cada um dos convidados e dos alunos participantes do projeto em meio a palmas calorosas. A partir daquele momento o sentimento que tomou conta de toda a equipe parecia ser o de dever cumprido. Deparamo-nos ainda, observando as reações dos bolsistas que trabalharam arduamente no projeto, com a sensação de que o resultado foi muito positivo na formação docente, especialmente por ouvirmos durante uma pequena auto avaliação feita ao final da atividade frases como: "estou no caminho certo!", "é isso que quero pra minha vida!" ou "eu também quero ajudar a transformar vidas!". 
Maria Andréa A. Carmo, Anderson A. G. de Oliveira | p. X-Y Trilhas de um (im)provável caminho: das...

Ainda no mesmo dia tomados por sentimentos múltiplos entre eles o da incerteza, afinal, não sabíamos como os demais alunos iriam receber o material, uma segunda sessão foi organizada no pátio da escola para todos os alunos do turno noturno e, ao exibir o vídeo documentário, já pronto e editado, o resultado não poderia ser diferente. Entre risos e lágrimas os alunos se abraçavam e nos agradeciam. Foi nítida a aprovação e o reconhecimento de suas histórias ali apresentadas, pois naqueles 22 minutos não estavam professores, bolsistas ou diretor, estavam alunos, pais, mães, irmãos, tios, enfim, eles estavam ali, falando por eles e para eles. Filhos reconheciam pais, pais se emocionavam em ver seus filhos e todos se identificavam pela rotina de vida, pelos problemas enfrentados, obstáculos vencidos e objetivos que ainda pretendiam alcançar.

Ao exibirmos o documentário para os demais estudantes da escola nos turnos da Manhã e da Tarde, os resultados e reações ao documentário não cessaram. A exemplo da Escola Estadual Lourdes de Carvalho, a Escola Estadual Professor Ederlindo Lannes Bernardes também se via pela mídia, quase sempre de forma depreciativa, especialmente por se tratar de escolas situadas em regiões periféricas. Mas, o projeto resultante deste vídeo documentário levou à construção de uma reportagem ${ }^{15}$ para a TV Universitária, vinculada a Universidade Federal de Uberlândia, o que gerou uma nova percepção por parte dos alunos e da comunidade em enxergar a escola e os projetos nela desenvolvidos, de uma forma diferente. Talvez, com este e outros trabalhos, seja possível escapar às evidências de que a escola reproduz e fortalece as desigualdades sociais, oportunizando aos estudantes mudanças em suas percepções e autorrepresentação.

\section{O PIBID E A FORMAÇÃO DOCENTE}

\footnotetext{
15 Matéria exibida na TV Universitária UFU sobre o vídeo documentário "Educação: Transformando realidades" disponível em: https://www.youtube.com/watch?v=iIPAGi7vOj8\&t=3s
} 
Maria Andréa A. Carmo, Anderson A. G. de Oliveira | p. X-Y Trilhas de um (im)provável caminho: das...

Diante das experiências desta atividade e dos resultados que pensamos ter alcançado, fizemos algumas questões com a intenção de compreender a relevância deste tipo de ação para a formação docente. Buscamos assim, avaliar em que medida estas experiências didáticas compõem o processo de formação? Quais os sentidos e significados destas atividades para os futuros docentes? De que maneira a escola contribui com esta formação?

Nossa intenção não é a de responder definitivamente estas questões, mas de apontar algumas possibilidades de análises a partir das avaliações realizadas pelos bolsistas que compuseram a equipe do subprojeto História durante as atividades realizadas e aqui pensadas.

Em um primeiro momento, avaliamos que o Programa possibilitou eficazmente uma aproximação entre a universidade e a escola básica e, tal movimento se refletiu entre os licenciandos como uma proposta de integração entre teoria e prática, entre os saberes adquiridos no curso de licenciatura e a realidade escolar e as práticas docentes, como relata uma estudante bolsista.

A Escola Estadual Ederlino Lannes Bernardes foi fundamental na minha formação, a graduação não poderia me dar tanto conhecimento prático, quanto estar naquela escola me deu. Conviver com os alunos e prestar atenção nos outros professores ajudou a reflexão de como atuar como professora no futuro. (Kathleen Loureiro - Bolsista PIBID)

Esta experiência parece ter iniciado o processo de construção ou formação de uma identidade docente, pensando que esta não é construída somente no período da formação inicial, "mas mediante um acúmulo de significados e representações carregados de valores, concepções e referências, os quais estão embutidos socioculturalmente da própria vivência do licenciando em seu histórico escolar"(OBARA, 2017, p. 981).

A vivência do licenciando parece instigar sua percepção sobre os processos de ensino-aprendizagem. E a sua participação no Programa o faz mediar e refletir sobre o papel da escola na sociedade e como os estudantes 
Maria Andréa A. Carmo, Anderson A. G. de Oliveira | p. X-Y Trilhas de um (im)provável caminho: das...

deveriam se relacionar com ela. Nessa direção aponta a narrativa de outro bolsista.

Estas atividades foram de suma importância para minha formação como docente por me ajudar a compreender a importância da relação dos alunos com a escola. É necessário que os alunos se identifiquem, queiram participar do universo escolar e entendo que esta relação é primordial e uma das bases para uma melhor qualidade de ensino. (Hugo Lima - Bolsista PIBID)

Há, aqui, a compreensão de que a escola deve dialogar com a realidade dos seus alunos e estes devem se reconhecer nela. Com esta percepção, tem-se, também, a perspectiva de uma troca de experiências e aprendizados contínuos também aos docentes a partir de sua relação com os estudantes e suas histórias, como relata outra bolsista.

Os alunos do EJA nos trouxeram uma carga de experiências no campo profissional e pessoal, ao ouvirmos aquelas histórias, pudemos notar o quão importante é a educação para essas pessoas e qual a real importância do professor para a formação do aluno. (Izabella Leles - Bolsista PIBID)

Entendemos que esta "real importância do professor para a formação do aluno" pode ser a avaliação realizada sobre a efetiva participação do professor no processo de ensino-aprendizagem e a sua responsabilidade social para com a escola e os sujeitos aprendizes. Sua interação com as histórias destes estudantes e o seu grau de envolvimento com estas histórias no ato de ensinar. Pensamos, como Nóvoa (2000, p. 48) que a “'refundação' da escola passa pelo professor (...) e seu papel é essencial para que a escola seja recriada como espaço de formação individual e de cidadania democrática".

Muitas são as possibilidades de avaliação e reflexão acerca dos projetos e atividades desenvolvidos pelo PIBID nas escolas da rede pública em que atuamos enquanto equipe, mas destacamos que para a formação docente o Programa se constituiu em importante instrumento, como aponta um dos bolsistas. 
Entendo que nossa formação como licenciados é impactada por este tipo de projeto que dialoga profundamente com a escola e as realidades de cada indivíduo que dela participa. (Geovan Santos - Bolsista PIBID)

De modo geral, a inserção na escola com o apoio teórico e acompanhamento constituem-se importante ferramenta na formação docente. Esta parece modificar a visão que os estudantes de licenciatura possuem da escola pública ao ingressarem no curso de licenciatura. Parece ainda possibilitar a avaliação e análise de sua própria constituição enquanto docente, capaz de desenvolver habilidades para atuar na futura profissão aprendendo a lidar com a especificidade de cada escola e público atendido perseguindo-se o objetivo do ensino-aprendizagem em História e o respeito ao sujeito aprendiz.

\section{CONSIDERAÇÕES FINAIS}

Ao longo da experiência como supervisor e coordenadora do PIBID - Sub projeto História em Uberlândia, atuando entre os anos de 2014 e 2018, nas escolas Estadual Professor Ederlindo Lannes Bernardes, Estadual Lourdes de Carvalho e Estadual João Rezende, tivemos nos vários encontros e atividades com os pibidianos, a possibilidade de observar, refletir e avaliar como este Programa se constituiu em importante ferramenta na articulação entre universidades e escolas de educação básica de modo a conferir novas significações para ambas, no sentido, de oportunizar e repensar os cursos de formação docente tendo como horizontes de transformação a realidade que os discentes da universidade passaram a experimentar de forma efetiva. Assim como a possibilidade que tiveram de realizar intervenções que dinamizam o seu processo de formação no âmbito das práticas de ensino e aprendizagem tendo como desafio, construir práticas que contribuam para a transformação da realidade social em que atuam enquanto pibidianos. 
Maria Andréa A. Carmo, Anderson A. G. de Oliveira | p. X-Y Trilhas de um (im)provável caminho: das...

Seja qual for a escola em que o PIBID se insira, temos a plena convicção de que infere uma grande transformação e movimento para e na instituição de ensino. E, para além de auxiliar na formação de professores, o PIBID tem ainda seu papel social, dando dinamicidade ao processo educacional, exigindo do profissional que está em sala e dos futuros docentes muito estudo, pesquisa e diálogo para se trabalhar com pouco ou quase nenhum recurso, levando-se em consideração que muitos dos projetos desenvolvidos e o que foi aqui descrito não tiveram financiamento, embora tenham contado com o apoio de laboratórios da Universidade Federal de Uberlândia. A criatividade e a vontade fazem parte desse movimento necessário dentro de um ambiente escolar.

Ao olharmos para trás, temos clareza de que conseguimos responder a nós mesmos o por que continuamos na profissão persistindo perante tantos percalços e problemas. O resultado positivo de cada projeto desenvolvido através do PIBID em sala de aula ou no ambiente escolar, em especial a produção deste vídeo documentário, reforçam que tornar a escola dinâmica, viva, atuante e responsável socialmente é possível. Reiteramos que o Programa Institucional de Bolsa de Iniciação a Docência não é o único fator de transformação da educação, mas suas ações em conjunto com profissionais, escolas e estudantes em formação que realmente valorizam e acreditam na educação são fundamentais e tornaramse propulsoras de ações múltiplas cujos resultados só fazem tornar a educação brasileira melhor a cada dia.

\section{REFERÊNCIAS BIBLIOGRÁFICAS:}

DI PIERRO, M. C. A educação de jovens e adultos no Plano Nacional de Educação: avaliação, desafios e perspectivas. Educação e Sociedade, Campinas, v. 31, n. 112, set. 2010.

FREIRE, Paulo. Pedagogia da Autonomia. São Paulo: Paz e Terra, 1996. A Educação na Cidade. São Paulo: Cortez, 1991. 
GATTI, Bernardete Angelina; BARRETTO, Elba Siqueira de Sá; AFONSO ANDRÉ, Marli Eliza Dalmazo de. Políticas docentes no Brasil: um estado da arte. Brasília: UNESCO, 2011.

HADDAD, S.; DI PIERRO, M. C. Escolarização de jovens e adultos. Revista Brasileira de Educação, Rio de Janeiro, n. 14, p. 108-130, maio/ago., 2000.

NÓVOA, António. Formação de professores e trabalho pedagógico. Lisboa: EDUCA, 2000.

OBARA, Cássia Emi; BROIETTI, Fabiele Cristiane Dias; PASSOS, Marinez Meneghello. Contribuições do PIBID para a construção da identidade docente do professor de Química. Ciênc. Educ., Bauru, v. 23, n. 4, p. 979-994, 2017.

TAUCHEN, Gionara; DEVEVHI, Catia Piccolo Viero; TREVISAN, Amarildo Luiz. Interação universidade e escola: uma colaboração entre ações e discursos. Rev. Diálogo Educ., Curitiba, v. 14, n. 42, p. 369-393, maio/ago. 2014. 